\title{
Simulation of global warming effect on outdoor thermal comfort conditions
}

\author{
${ }^{1}{ }^{*}$ Gh. R. Roshan; ${ }^{1}$ F. Ranjbar; ${ }^{2}$ J. A. Orosa \\ ${ }^{1}$ Department of Physical Geography, Faculty of Geography, University of Tehran, Tehran, Iran \\ ${ }^{2}$ Department of Energy, University of A Coruña, A Coruña, Spain \\ Received 4 February 2010; $\quad$ revised 5 April 2010; accepted 15 May 2010; availaE@Honline 1 June 2010
}

\begin{abstract}
In the coming decades, global warming and increase in temperature, in different regions of the world, may change indoor and outdoor thermal comfort conditions and human health. The aim of this research was to study the effects of global warming on thermal comfort conditions in indoor ambiences in Iran. To study the increase in temperature, model for assessment of greenhouse-gas induced climate change scenario generator compound model has been used together with four scenarios and to estimate thermal comfort conditions, adaptive model of the American Society of Heating, Refrigerating and Air-conditioning Engineers has been used. In this study, Iran was divided into 30 zones, outdoor conditions were obtained using meteorological data of 80 climatological stations and changes in neutral comfort conditions in 2025, 2050, 2075 and 2100 were predicted. In accordance with each scenario, findings from this study showed that temperature in the 30 zones will increase by 2100 to between $3.4^{\circ} \mathrm{C}$ and $5.6^{\circ} \mathrm{C}$. In the coming decades and in the 30 studied zones, neutral comfort temperature will increase and be higher and more intense in the central and desert zones of Iran. The low increase in this temperature will be connected to the coastal areas of the Caspian and Oman Sea in southeast Iran. This increase in temperature will be followed by a change in thermal comfort and indoor energy consumption from $8.6 \%$ to $13.1 \%$ in air conditioning systems. As a result, passive methods as thermal inertia are proposed as a possible solution.
\end{abstract}

Keyw ords: Bioclimatic; Energy; Forecast; General circulation models

\section{INTRODUCTION}

Human life has evolved within the environment of temperature, humidity, and solar radiation that has not varied much for thousands of years; therefore, human beings and the flora and fauna with which earth planet is shared, have limited capacity to adapt to rapid or extreme climatic changes (Berry et al., 2009). However, consumption of fossil fuel by humans has increased carbon dioxide and other greenhouse gases. As a result, scenarios from the international panel of climate change (IPCC) and general circulation models (GCM) forecast that the rise in concentration of greenhouse gases may increase global temperature (Radhi, 2009; Willem and Christopher, 2009). Besides, new climatic models forecast that if the level of carbon dioxide continues to increase, the average temperature of the earth will increase during this century from about 1.4 to $5.8^{\circ} \mathrm{C}$ (Pandy, 2005).

*Corresponding Author Email: ghr.rowshan@gmail.com Tel.: +98917 1350 305; Fax: +9821 66404366
This climatic changes and global warming may have harmful effects on human life, such as drought, destructive floods, increase in the frequency and intensity of hurricanes and the increase in cold/warm waves in different regions of the world which imperils human health. Furthermore, based on reports of the World Health Organization (WHO), the number of dead owing to climatic changes will reach 150,000 humans in many regions of the world; $3 \%$ of the total number of the dead (Piotrowicz, 2009).

Another immediate effect of the rise in temperature in the coming decades is that it may change human thermal comfort conditions. The ASHRAE consider thermal comfort as mental conditions that indicate satisfaction with thermal environment (ASHRAE 55, 2004; Lin and Deng, 2006; Abbaspour et al., 2008; Etemad-Shahidi et al., 2010). This environment depends on the interaction and mutual effect of temperature, average radiation temperature, rate of airflow and air 
humidity (Prek, 2006). For example, when environmental temperature is normal and lets human body maintain its thermal balance without perspiration or trembling, a human feels relief and, when the humidity is increased on skin surface, it may disturb human comfort (Miller, 2008). As a result, global warming and increase in temperature will change the neutral thermal comfort sensation and human health.

Studies on human comfort, based in thermodynamic analysis of a human's thermal body (Prek, 2006), have been conducted using different indexes. These indexes have studied the effects of global warming and climatic changes on bioclimatic, human comfort and stress conditions (Sakoi et al., 2007; Tian and Love, 2008; Zaman, 2010). These results could be applied in real situations, particularly semi-open environments in Greece (Matzarakis and Mayer, 1997) and Australia (Spagnolo and Dear, 2003) and in urban areas (Gulyas et al., 2006). Furthermore, during the last few decades, it developed a series of studies about the relationship between climatic changes and mortality in large cities in the United States (Kalkstein and Greene, 1995) and England and Wales (Langford and Bentham, 1995; Martens, 1998). At the present time, it has developed a special interest on these indexes in focus comfort studies on related fields and simulation tests for energy saving (Panjeshahi and Ataei, 2008; Orosa, 2009; Zeiler and Boxem, 2009). Owing to these indexes, the future comfort temperature is proposed and, in consequence, if it is needed, a heating ventilation and air conditioning (HVAC) system.

These studies present special interest in some countries, particularly Iran. In Iran, statistics show that buildings account for about $39 \%$ of total energy consumption (Foruzanmehr and Nicol, 2008); it is equal to $30 \%$ of its annual oil income, with $50 \%$ being wasted. Finally, using and wasting energy, air-conditioned energy-dependent buildings emit more greenhouse gases that drive global warming (Foruzanmehr and Nicol, 2008).

Thus, there is a need for urgent action and here, the buildings are the first work point. Besides, most of the $20^{\text {th }}$ century buildings are dependent on air-conditioned systems and electricity that rely on fossil fuels; they are increasingly unable to adapt to a warming climate.

In contrast to modern buildings, vernacular architecture in many regions is more adaptable to the environment. The buildings in the desert are equipped with thick walls, wind catchers, courtyards, ponds, fountains, rich gardens and vaulted chambers, according to principles evolved over many generations. As a result, these buildings use local construction materials, passive cooling and heating, and renewable energy.

In spite of its importance, traditional architecture and its methods and strategies, especially those of the hot and arid climates of Iran, are undervalued and not used in new constructions. Besides, few attempts have been made to investigate the local architecture of Central Iran. Moreover, there are few comprehensive studies on the relationship between temperature increase resulting from global warming and the effectiveness of passive cooling systems (Roshan et al., 2009; Praveena and Aris, 2010). The extent, to which traditional systems could provide comfort conditions in these buildings, has not been the subject of many studies and the way buildings can withstand extremely hot summer temperatures has not been well addressed.

This research was conducted for the purpose of studying effects of global warming on the limit to outdoor thermal comfort conditions in Iran. For this reason, according to global warming models, thermal comfort conditions in Iran have been studied for 2025, 2050, 2075 and 2100.

Finally, this research finished at the end of January, 2010 as a common work between researchers in Department of Geography of University of Tehran in Iran and Department of Energy and M.P., University of A Coruña, in Spain.

\section{MATERIALS AND METHODS}

Climate change models

To study bioclimatic conditions of the last decade, the data from climatological stations located in the 30 zones of Iran, for a 25-year period (1981-2005), have been used for the purpose of forecasting and modeling temperature change owing to an increase in greenhouse gases.

In this study, to predict the global warming effect, MAGICC SCENGEN compound model was used. MAGICC consists of a set of interrelated simple models. This model uses some parameters as input in modeling process; the most important of which is climatic sensitivity. The regional and global SCENGEN is not only a climatic model, but it also includes results of many GCMs, as well as a set of global perceptional data and four sets of regional climate data (Kont et al. 2003). 
Calculations for Iran's UKHADGEM (United Kingdom Hadley Center Global Environment Model) have been used for four IPCC-suggested scenarios. Iran country located between 25 and $40^{\circ}$ latitude and 44 and $63.5^{\circ}$ east longitude could be divided into 30 geographical zones where temperature changes have been modeled. Due to such a geographical situation, provinces located in the west and northwest are not included in the zone, with 2.5 degree division power. Table 1 and Fig. 1 show the geographical situation and boundaries of the 30 zones.

\section{Structure of MAGICC SCENGEN model}

MAGICC is a model for assessment of gas-induced climate changes and is comprised of a set of simple interrelated models. This model makes use of some parameters as input in the simulation process, the most important of which is climate sensitivity. The fact is that this model is used for the purpose of forecasting and simulating climate parameters with regard to these inputs for the future years and for different regions. Indeed, MAGICC is not a GCM model but it uses the data of some climate models to simulate GCM models behavior for the considered region. In other words, this model is composed of a gas cycle, as well as snow melting models which allows the user to determine the average global temperature changes and the datum level changes according to greenhouse gases dispersion (Kont et al., 2003).

SCENGEN is a regional and global scenario generator. This model is not only a climatic model but a simple database, including results of many GCMs, as well as a set of global perceptional data and four sets of regional climate data. The fact is that SCENGEN is simple software which allows the user to make use of the results of MAGICC model and the general circulation models. It also pave the way for the user to recognize the consequences using different presuppositions in regard to climate system parameters. The scenarios of this model are forecasted from dispersion of greenhouse gases in the future, using different hypotheses in relation to human activities, policies and technology applications, etc. (Kont et al., 2003). By this method, 20 GCM models can be used separately or in groups. In case of selecting several GCM models, the program averages them and produces a compound model of climate change.

\section{Optimal indoor temperature}

However, in accordance with (Foruzanmehr and Nicol, 2008), once climate change is predicted, it will be interesting to define the effect of future outdoor temperature over indoor ambiences and, in particular, the effect of passive methods to improve these future

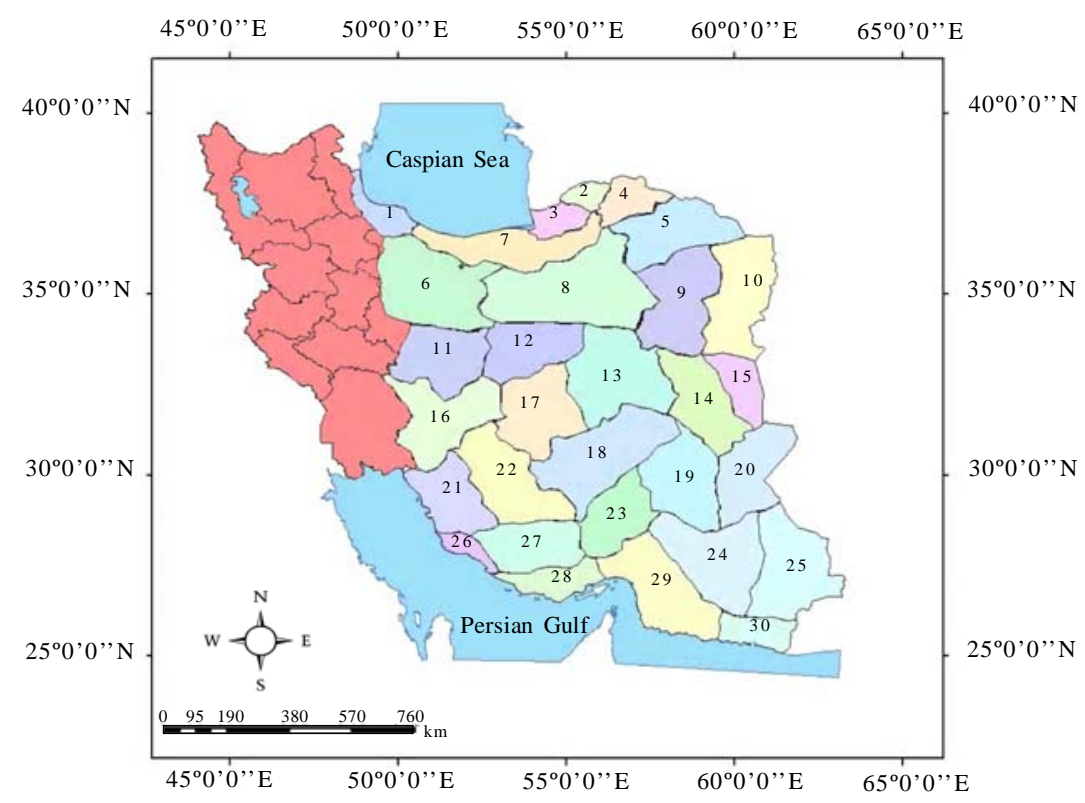

Fig. 1: Division of the 30 zones of Iran based on the MAGICC SCENGEN model 
Global warming effect on outdoor thermal comfort

Table 1: Calculation zones location in MAGICC SCENGEN model

\begin{tabular}{|c|c|c|c|}
\hline Position of Provinces & Longitude (E) & Latitude $(\mathrm{N})$ & Regions \\
\hline West Caspian sea -Ghilan & $50-52.5$ & $37.5-40$ & 1 \\
\hline Northwest Gulestan & $52.5-55$ & $37.5-40$ & 2 \\
\hline Gulestan & $55-57.5$ & $37.5-40$ & 3 \\
\hline North Khorasan & 57.5- 60 & $37.5-40$ & 4 \\
\hline North Khorasan Razavi & $60-62.5$ & $37.5-40$ & 5 \\
\hline North Esfahan- East Arak: East Ghazvi: Qom: Tehran & $50-52.5$ & 35- 37.5 & 6 \\
\hline Mazandaran-West Semnan & 52.5- 55 & $35-37.5$ & 7 \\
\hline South and East Semnan: North Yazd & 55- 57.5 & $35-37.5$ & 8 \\
\hline West Khorasan Razavi & $57.5-60$ & $35-37.5$ & 9 \\
\hline East Khorasan Razavi & $60-62.5$ & 35- 37.5 & 10 \\
\hline West Esfahan & $50-52.5$ & $32.5-35$ & 11 \\
\hline East Esfahan & $52.5-55$ & $32.5-35$ & 12 \\
\hline East Yazd & $55-57.5$ & 32.5- 35 & 13 \\
\hline West of southern Khorasan & 57.5- 60 & 32.5- 35 & 14 \\
\hline East of Southern Khorasan & $60-62.5$ & $32.5-35$ & 15 \\
\hline Kohgiloye: Boyer Ahmad: Chahar Mahal Bakhtiyar: South Isfahan & $50-52.5$ & $32.5-35$ & 16 \\
\hline Southeast Esfahan: South Yazd & $52.5-55$ & $30-32.5$ & 17 \\
\hline West Yazd: North and Northwest Kerman & $55-57.5$ & $30-32.5$ & 18 \\
\hline Northeast Kerman: South of Southern Khorasan & $57.6-60$ & $30-32.5$ & 19 \\
\hline North Sistan and Balochistan & $60-62.5$ & $30-32.5$ & 20 \\
\hline Boshehr: West Fars & $50-52.5$ & $27.5-30$ & 21 \\
\hline East Fars & 52.5- 55 & $27.5-30$ & 22 \\
\hline Northwest Hormozgan: Southeest Kerman & $55-57.5$ & $27.5-30$ & 23 \\
\hline East Kerman- West Sistsn and Balochistan & $57.5-60$ & $27.5-30$ & 24 \\
\hline East Sistan and Balochistan & $60-62.5$ & $27.5-30$ & 25 \\
\hline South Boshehr & $50-52.5$ & $25-37.5$ & 26 \\
\hline South Fars & $52.5-55$ & $25-37.5$ & 27 \\
\hline West Hormozgan & 55- 57.5 & $25-37.5$ & 28 \\
\hline East Hormozgan: South Kerma: -Southwest Sistan & $57.5-60$ & $25-37.5$ & 29 \\
\hline Southeast Sistan and Balochistan & $60-62.5$ & $25-37.5$ & 30 \\
\hline
\end{tabular}

conditions. Besides, the following three main aspects of vernacular buildings must be studied and analysed.

(1) physical and cultural;

(2) thermal comfort;

(3) energy performance aspects of vernacular buildings in comparison with modern buildings.

Besides, from the cultural point of view, Iran's existing courtyards built 130 years ago showed a good effect of thermal mass in modulating the temperature inside the house. In addition, closed doors and windows facing northeast and southwest were another reason for this phenomenon (Foruzanmehr and Nicol, 2008). As a result, it became evident that this passive courtyard building, in the central parts of Iran, works very well in terms of modulating the temperature swings, lowering the ambient temperature by the use of different traditional passive cooling strategies and providing the occupants with various temperatures during the hot summer. If the thermal comfort aspect is considered in accordance with (Nicol, 2004), in theory at least, the predicted mean vote (PMV) should predict the temperature at which people are comfortable regardless of the local conditions. The equations, on which it is based, take account of changes in clothing and activity; thus, it should be able to predict thermal sensation, irrespective of where it is used. Despite this, in tropical conditions, it fails and suggests a higher expected PMV that implies a higher cooling energy. To solve this problem, empirical findings of field surveys can be used as a guide for informing the design of buildings to provide comfortable conditions. For example, recent research, such as 'smart controls and thermal comfort (SCATs)' project (Nicol and Humphreys, 2007), funded by the European Commission in 1997-2000, sampled the indoor conditions in 26 offices in various countries, particularly France, Greece, Portugal, Sweden and the United Kingdom. After relating the sampled values with the survey's results, it has concluded that the comfort temperature $\left(T_{c}\right)$ is a function of the exponentially weighted running mean of the daily mean outdoor temperature (Trm) with $\alpha=0.8$, as seen 
in Eqs. 1 and 2. This $\alpha$ is a constant between 0 and 1 , which defines the speed at which the running mean responds to the outdoor temperature.

For running operation:

$T=0.33 \cdot T_{r+}+18.8$

For heated or cooled operation:

$T_{c}=0.09 \cdot T_{r m}+22.6$

In accordance with (Fransson et al., 2007), today they rely in subjective and objective indicators for assessing the indoor conditions (ISO, 1995; Orosa, 2009). Furthermore, in (Fransson et al., 2007), regression analyses indicated that the subjective sensory ratings were significantly better than objective indicators at predicting overall-rated indoor comfort.

In these studies, Nicol and Humphrey challenged steady-state comfort theories with the introduction of adaptive comfort theory (Nicol and Humphreys., 1973; McCartney and Nicol, 2002). The theory shows that occupants of an indoor ambience can support conditions over steady-state owing to the fact that they can adapt to their environment. Eight years later, in 1978, Humphrey induced the argument that this comfort temperature is related with the external temperature at the location (Humphreys, 1978), as seen in Eq. 3.

$T_{c}=b+a T_{o}$

Where, $\mathrm{T}_{\mathrm{c}}$ is the comfort temperature and $\mathrm{T}_{\mathrm{o}}$ is the outside temperature index and $\mathrm{a}, \mathrm{b}$ are constants.

In (Nicol and Humphreys, 2002), the comfort temperature in free-running buildings depends on outdoor temperature. Besides, Humphrey and Nicol (Humphreys and Nicol, 2000) presented Eq. 4 and ASHRAE (2004) proposed a similar model in Eq. 5 (Orosa, 2009).

$$
\begin{aligned}
& T_{c}=13.5+0.54 \cdot T_{o} \\
& T_{c}=17.8+0.31 \cdot T_{o}
\end{aligned}
$$

In (Nicol and Humphreys, 2002), the relationship between the desired indoor temperature and the range of outdoor temperatures showed that night cooling is likely to be a viable way to keep the building comfortable during the day in summer, or to calculate whether passive solar heating will be enough in winter.
It was employed in Islamabad, Pakistan, and showed the temperature differential between outdoors and indoors, which the building had to achieve to remain comfortable indoors (Nicol, 2004); it will be applied under predicted outdoor temperatures in the next few years, as a consequence of climatic change.

Finally, the energy performance aspect must be considered. Once obtained, the future neutral temperature of Iran indoor ambiences will be compared with the present neutral temperature of thermal comfort. With these values, the perceptual increment of energy required to cool indoor air can be calculated to respect present conditions. Results clearly show that, if in this climate and type of building, a mechanical cooling and heating system is needed or a passive climate control method is sufficient.

The methodology described in (Olalekan et al., 2006; Orasa and Oliveira, 2009) was employed to calculate energy consumption needed to achieve ideal comfort conditions. In this research, seasonal energy consumption is estimated as a function of the ventilation rate of outdoor air and enthalpy difference between present and future indoor neutral air conditions and present and future outdoor conditions, as seen in Eqs. 6, -8.

$Q=\dot{m}_{\text {ventilatio }} \int \Delta h \cdot d t$

Where;

$$
\begin{aligned}
& \Delta h=h_{\text {futureoutdoor }}-h_{\text {future indoor }} \\
& \Delta h=h_{\text {presentoutdoor }}-h_{\text {presentindoor }}
\end{aligned}
$$

$\mathrm{h}_{\text {future }}$ is the future indoor air enthalpy after climate change effect and $h_{\text {present }}$ is the present indoor air enthalpy.

In order to study thermal neutral comfort conditions in Iran, comfort temperature-adapted index presented by ASHRAE (2004) has been used in Eq. 5. To apply this method, it is to be taken into account that during summer temperature floats freely. This procedure pave the way to define the expected change in energy consumption.

\section{RESULTS AND DISCUSSION}

Results of this temperature simulations for years 2025's, 2050's, 2075's and 2100's were analysed and represented in Figs. 2-6. 
Gh. R. Roshan et al.

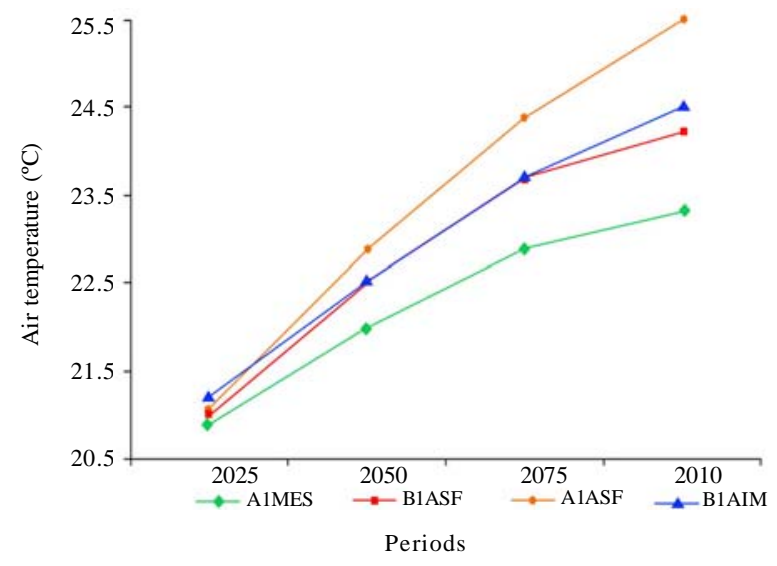

Fig. 2. Temperature changes in Iran by 2100

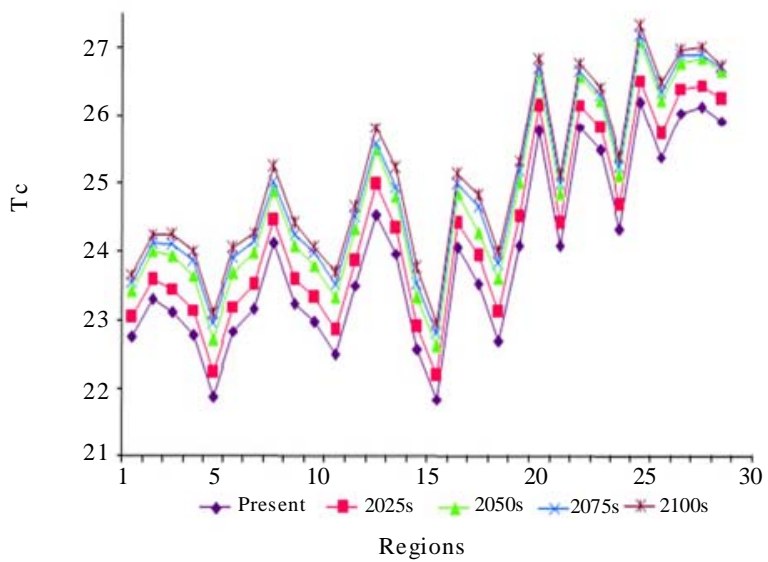

Fig. 4: Tc changes from the present time till 2100, based on the BIASF scenario

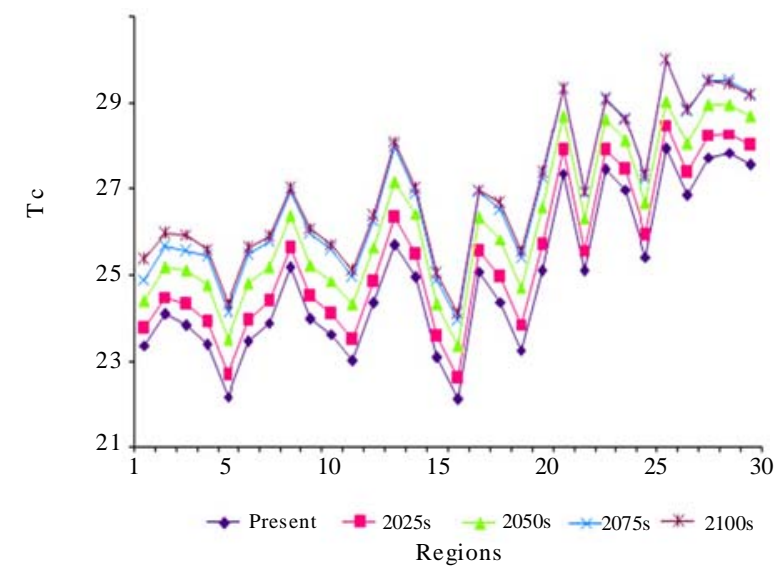

Fig. 6: Tc changes from the present time till 2100, based on the AIASF scenario

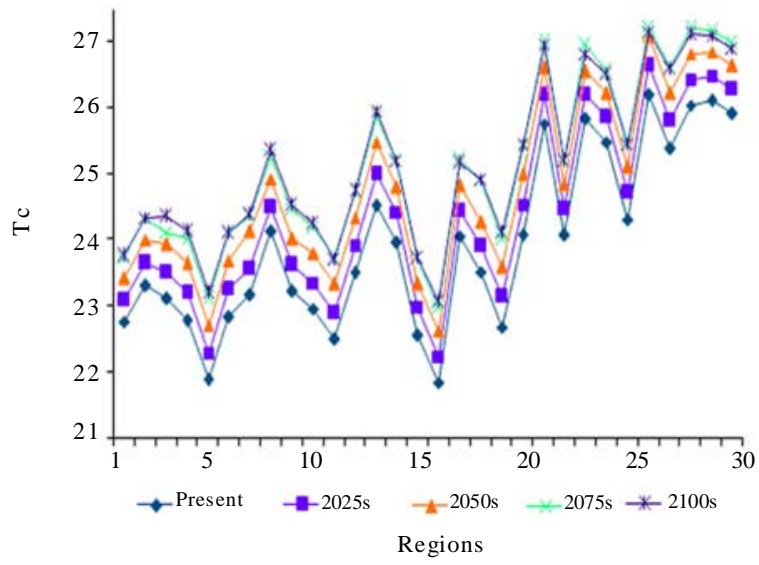

Fig. 3. Tc changes from the present time till 2100, based on the AIMES scenario

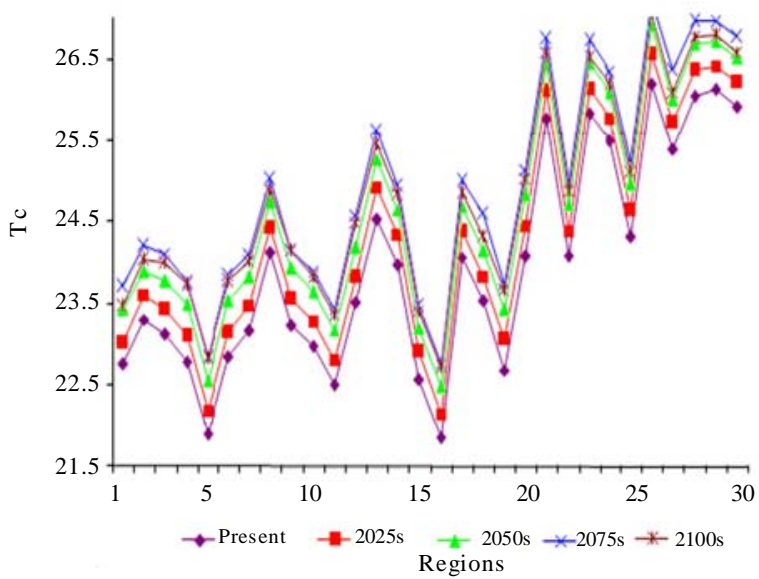

Fig. 5: Tc changes from the present time till 2100, based on the AIAIM scenario

\section{Iran's temperature changes}

In order to study temperature changes in the 30 zones of Iran, data from the 80 climatological stations have been selected to show the present temperature and compare it with the temperature in the coming decades. Besides, four scenarios suggested by IPCC have been used for studying temperature changes in the coming decades: BIAIM, AIASF, BIASF and AIMES.

The following interpretation of each of these scenarios will be paid by:

\section{Scenarios of A1 family}

The hypotheses of these scenarios are mainly based on the followings: 
- Increase of the education level of the families.

- Increase of the investment rate and inventions in the field of education, technology and energy in national and international levels.

- The international activity and dynamism of the population, ideas and technology.

- The scenarios of A1 family reflect the ambiguities in the field of energy resources development and technologies' changes in the changing world.

\section{Scenarios of B1 family}

The main element of this family is based upon the principal that the future will enjoy a great deal of social and environmental awareness aiming at stable development and on this basis, it tries to forecast the future ambiguities. In better words, based on the scenarios of this group, the governments, the businessmen, the media, and the people will pay more attention to environmental and social aspects of development. In general, in the coming decades, most of the zones in Iran will experience a considerable temperature rise, as seen in Fig. 1. This temperature rise will be higher and more intense in some regions than others and the maximum rise is related to the AIASF scenario. According to the used scenarios, the maximum increase in temperature is related to zones 12 (East Isfahan), 13 (East Yazd), 18 (West Yazd, North and Northwest Kerman), 19 (Northeast Kerman, South of southern Khorasan) and 20 (North Sistan Baluchestan). The least rise in temperature in the coming decades is related to zones 1 (West Caspian Sea, West Gilan), 2 (Northwest Golestan) and 3 (Golestan). Regarding the effect of greenhouse gas increase and owing to the results of scenarios, the highest increase in temperature is related to the internal and lower parts of Iran. At present, these parts have an arid climate and are far from humidity resources.Further from the central regions of Iran and close to south and north coastal areas, the rate of temperature rise, in the coming decades decreases. In fact, regions close to the coast and south and north latitudes will experience a lower increase in temperature in the future, in comparison with the central and internal regions. In general, average temperature in the 30 zones of Iran is about $19.9^{\circ} \mathrm{C}$ at present. The average rise in temperature by 2100 will be 4.6 based on the AIMES scenario, $4.3^{\circ} \mathrm{C}$ on BIASF, $5.6^{\circ} \mathrm{C}$ on AIASF and $3.4^{\circ} \mathrm{C}$ on BIAIM.

\section{Changes in thermal comfort conditions}

Based on results of the scenarios, the increase in Tc from the present time till 2050 will be considerable and intense. If the increasing trend in temperature is paid attention, thermal comfort conditions will experience some changes in the coming decades. Thermal comfort conditions in Iran have been studied, based on the adaptive method suggested by ASHRAE (2004).

Fig. 3 shows $T_{c}$ changes based on AIMES scenario in 30 zones of Iran. Results of AIMES that Tc in all 30 zones will have an average increase of $1.2^{\circ} \mathrm{C}$ by 2100 and that the maximum increase is related to Central Iran and desert regions. In fact, these regions are known as zones 18, 19, 20 which include northwest Kerman, east Yazd, south of southern Khorasan and north Sistan Baluchestan.

Based on BIASF scenario, the maximum increase of Tc is related to internal parts of Iran, such as zones 13, 14, 18, 19 and 20, which, in fact, include internal and arid regions of Iran. The increase in $\mathrm{T}_{c}$ value will be about $1.3{ }^{\circ} \mathrm{C}$ and the least increase is related to coastal regions of the Caspian Sea and regions close to the Coast of Oman Sea in southeast Iran. Level of increase in these regions will be about $0.9^{\circ} \mathrm{C}$ by 2100 .

From among the used scenarios, AIASF shows the highest increase in Tc value for Iran by about 1.5 ${ }^{\circ} \mathrm{C}$. Results of this scenario show that zones 13,18 , 19 and 20 will experience the most increase by 2100 . In particular, zone 13 includes Yazd Province where the temperature will be about $1.8^{\circ} \mathrm{C}$, which indicates the maximum increase from among the 30 zones. The minimum increase of $T_{c}$ is related to the southeast region of Iran, which includes zones 29 and 30.

AIAIM scenario shows the least increase of Tc by 2100. Based on results of this scenario, Tc value will have an increase of $0.8{ }^{\circ} \mathrm{C}$ by 2100 . The maximum increase is related to zones 12,19 and 20, with an increase of about $1{ }^{\circ} \mathrm{C}$ that will be experienced in 2100 . Based on the same scenario, the least increase is related to the coastal zones of Caspian Sea, which include zones 1, 2 and southeast parts of Iran, which include zone 29 and 30 . In general and based on the average scenarios, the amount of increase in Tc by 2100 will be about $1.2^{\circ} \mathrm{C}$ in Iran.

\section{Energy consumption and passive methods \\ Once obtained, the future neutral temperature in indoor ambiences will be compared with the present}


Global warming effect on outdoor thermal comfort

Table 2: Present and future outdoor and indoor neutral temperature and energy consumption for 2100

\begin{tabular}{|c|c|c|c|c|c|c|}
\hline & $\begin{array}{l}\text { Outdoor } \\
\text { temperature } \\
\left({ }^{\circ} \mathrm{C}\right) \\
\end{array}$ & $\begin{array}{l}\text { Neutral } \\
\text { temperature } \\
\left({ }^{\circ} \mathrm{C}\right) \\
\end{array}$ & $\begin{array}{l}\text { Increment } \\
\text { of neutral } \\
\text { temperature }\end{array}$ & $\begin{array}{l}\text { Increment of } \\
\text { outdoor } \\
\text { temperature }\end{array}$ & $\begin{array}{l}\text { Cooling } \\
\text { degrees }\end{array}$ & $\begin{array}{l}\text { Increment of } \\
\text { energy } \\
\text { consumption }\end{array}$ \\
\hline AIMES & 24.5 & 25.4 & 1.39 & 4.6 & 3.2 & 11.2 \\
\hline BIASF & 24.2 & 25.3 & 1.30 & 4.3 & 3.0 & 10.5 \\
\hline AIASF & 25.5 & 25.7 & 1.70 & 5.6 & 3.9 & 13.1 \\
\hline BIAIM & 23.3 & 25.0 & 1.02 & 3.4 & 2.3 & 8.6 \\
\hline PRESENT & 19.9 & 24.0 & & & & \\
\hline
\end{tabular}

conditions. Results let us define the need of a HVAC system and its possible energy consumption. Furthermore, proposals of passive methods to prevent this situation could be obtained.

To calculate the energy consumption, before and after the climate change in each region, it must be simplified in Eqs. 6, 7 and 8. Besides, considering the now and future conditions, the same flow of outdoor air and indoor relative humidity, these equations can be defined as a direct function of neutral outdoor and indoor neutral temperatures. As a result, its relationship shows the proportional increment of energy consumption to cool the indoor ambience.

As commented earlier, in all 30 zones of Iran, an average increase of $1.2{ }^{\circ} \mathrm{C}$ will occur by 2100 . As a result, in accordance with the earlier simplifications of Eqs. 6-8, it will obtain an increment of $11.2 \%$ in accordance with AIMES scenario, $10.5 \%$ BIASF scenario, $13.1 \%$ AIASF scenario and $8.6 \%$ AIAIM scenario in the HVAC energy consumption, as seen in Table 2.

Finally, as commented earlier, this increment of energy consumption can be reduced preventing new building construction and HVAC system design and operation; for example, by passive methods of vernacular architecture, in particular building thermal inertia. Another solution, in accordance with (McCartney and Nicol, 2002) is to develop a control algorithm based on this equation that considers the weather conditions of each particular region. More research about the vernacular architecture and its advantages to control indoor ambiences must be developed.

\section{CONCLUSION}

This research has been conducted with the aim of studying thermal comfort conditions in Iran in the coming decades under the effect of global warming. Results of this study showed that, based on the used model and defined scenario, rise in temperature will be inevitable in Iran by 2100 . This increase in temperature will be more intense and higher in the central parts of Iran. Zones 12, 13, 18, 19 and 20 will experience the highest temperature rise by 2100 . In general and based on average of all the scenarios, temperature increase will be 4.5 degree by 2100 .

According to the expected rise in temperature in different parts of Iran, some changes will also occur in thermal comfort conditions. In this study, the method proposed by ASHRAE (2004); ( $T_{c}$ method) has been used to study thermal comfort conditions. Based on the scenarios, Iran will experience a rise in $\mathrm{T}_{\mathrm{c}}$ in the coming decades. From the 30 zones of Iran, the highest increase of $T_{c}$ is related to zones which include internal and lowlands of Iran which have hot and desert climate at present. During the coming decades, the minimum increase of $T_{c}$ will be related to zones which include the coastal zones of the Caspian Sea and Oman Sea in southeast Iran. Finally, the temperature increase will imply an increment of indoor energy consumption from $8.6 \%$ to $13.1 \%$ in air conditioning systems. As a result, passive methods, such as thermal inertia, are proposed as a possible solution.

\section{ACKNOWLEDGEMENTS}

The authors highly appreciate the three anonymous reviewers of IJEST who provided excellent suggestions for revision; also, provision of data and statistics from Iran Meteorological Organization (IRIMO) are acknowledged.

\section{REFERENCES}

Abbaspour, M.; Jafari, M. J.; Mansouri, N.; Moattar, F.; Nouri, N.; Allahyari, M., (2008). Thermal comfort evaluation in Tehran metro using Relative Warmth Index. Int. J. Environ. Sci. Tech., 5 (3), 297-304 (8 pages).

ASHRAE Standard 55. (2004). Thermal Environmental Conditions for Human Occupancy (ANSI Approved).

Berry, H. L.; Bowen, K.; Kjellstrom, T., (2009). Climate change 
and mental health: A causal pathways framework. Int. J. Public. Health, 55 (2) 123-132 (10 pages).

Etemad-Shahidi, A.; Zoghi, M. J.; Saeedi, M., (2010). An alternative data driven approach for prediction of thermal discharge initial dilution using tee diffusers. Int. J. Environ. Sci. Tech., 7 (1), 29-36 (8 pages).

Foruzanmehr, A.; Nicol, F., (2008). Towards new approaches for integrating vernacular passive-cooling system into modern building in warm-dry climates of Iran. Proceedings of conference: Air Conditioning and the low Carbon Cooling Challenge. Cumberland Lodge, Windsor, UK, 27-29 July. London.

Fransson, N.; Yästfjäll, D.; Skoog, J., (2007). In search of the comfortable indoor environment: A comparison of the utility of objective and subjective indicators of indoor comfort. Build. Environ., 42 (5), 1886-1890 (5 pages).

Gulyas, A.; Unger, J.; Matzarakis, A., (2006). Assessment of the microclimatic and human comfort conditions in acomplex urban environment: Modelling and measurements. Build. Environ., 41 (12), 1713-1722 (10 pages).

Humphreys, M. A.; Nicol, J. F., (2000). Outdoor temperature and indoor thermal comfort: Raising the precision of the relationship for the 1998 ASHRAE database of field studies. ASHRAE Transact., 206 (2), 485-492 (8 pages).

Humphreys, M. A., (1978). Outdoor temperature and comfort indoors. Build. Res. Pract., 6 (2), 92-105 (14 pages).

ISO 10551. (1995). Ergonomics of the thermal environmentAssessment of the influence of the thermal environment using subjective judgement scales.

Kalkstein, L. S.; Greene, J. S., (1997). An evaluation of climate/ mortality relationships in large U.S. cities and the possible impacts of a climate change. Environ. Health Perspect., 105 (1), 84-93 (10 pages).

Kont, A.; Jaagus, J.; Aunap, R., (2003). Climate change scenario and the effect of sea-level rise for Estonia. Glob. Plan. Chang., 36 (1-2), 1-15 (15 pages).

Langford, I. H.; Bentham, G., (1995). The potential effects of climate change on winter mortality in England and Wales. Int. J. Bioclimat., 38 (3), 141-147 (7 pages).

Lin, Z.; Deng, S., (2006). A study on the thermal comfort in sleeping environments in the subtropics- Developing a thermal comfort model for sleeping environments. Build. Environ., 43 (1), 70-81 (12 pages).

Martens, W. J., (1998). Climate change, thermal stress, and mortality change. Soc. Sci. Med., 46 (3), 331-344 (14 pages).

Matzarakis, A.; Mayer, H., (1997). Heat stress in Greece. Int J. Biometeorol., 41 (1), 34-39 (6 pages).

McCartney, K. J.; Nicol, J. F., (2002). Developing an adaptive control algorithm for Europe. Energy Build., 34 (6), 623635 (12 pages).

Miller, H., (2008). The attributes of thermal comfort. (Solution Essay) Ergonomic criteria for the design of "breathable" work chairs. http://www.hermanmiller.com/ MarketFacingTech/hmc/solution_essays/assets/se_ Attributes _ of_ Thermal _ Comfort.pdf.

Nicol, J. F., (2004). Adaptive thermal comfort standards in the hot-humid tropics. Energy Build., 36 (7), 628-637 (10 pages).
Nicol, J. F.; Humphreys, M., (2007). Maximum temperatures in European office buildings to avoid heat discomfort. Sol. Energy, 81 (3), 295-304 (10 pages).

Nicol, J. F.; Humphreys, M. A., (2002). Adaptive thermal comfort and sustainable thermal standards for buildings. Energ. Buildings., 34 (4), 563-572 (10 pages).

Nicol, J. F.; Humphreys, M. A., (1973). Thermal comfort as part of a self regulating system, in: Proceedings of the CIB Symposium on thermal comfort. Building Research Establishment, Watford, UK.

Olalekan, F.; Osanyintola, O. F.; Simonson, C. J., (2006). Moisture buffering capacity on hygroscopic building materials: Experimental facilities and energy impact. Energ. Buildings., 38 (10), 1270-1282 (13 pages).

Orosa, J. A., (2009). Research on the origins of thermal comfort. Eur. J. Sci. Res., 34 (4), 561-567 (7 pages).

Orosa, J. A.; Oliveira, A., (2009). Energy saving with passive climate control methods in Spanish office buildings. Energ. Buildings., 41 (8), 823-828 (6 pages).

Pandey, M., (2005). Global warming and climate change. Publisher Dominant Publishers and Distributors.

Panjeshahi, M. H.; Ataei, A., (2008). Application of an environmentally optimum cooling water system design in water and energy conservation. Int. J. Environ. Sci. Tech., 5 (2), 251-262 (12 pages).

Piotrowicz, K ., (2009). The occurrence of unfavorable thermal conditions on human health in central europe and potential climate change impacts: An example from cracow, Poland. Environ. Manage., 44 (4), 766-775 (10 pages).

Praveena, S. M.; Aris, A. Z., (2010). Groundwater resources assessment using numerical model: A case study in lowlying coastal area. Int. J. Environ. Sci. Tech., 7 (1), 135146 (12 pages).

Prek, M., (2006). Thermodynamical analysis of human thermal comfort. Energy, 31 (5), $732-743$ (12 pages).

Radhi, H., (2009). Evaluating the potential impact of global warming on the UAE residential buildings - A contribution to reduce the $\mathrm{CO}_{2}$ emissions., Build. Environ. 44 (12), 2451-2462 (12 pages).

Roshan, G. R.; Rousta, I.; Ramesh, M., (2009). Studying the effects of urban sprawl of metropolis on tourism-climate index oscillation: A case study of Tehran city. J. Geograph. Region. Plan., 2 (12), 310-321 (12 pages).

Sakoi, T.; Tsuzuki, K.; Kato, S. H.; Ooka, R.; Song, D.; Zhu, S. H., (2007). Thermal comfort, skin temperature distribution and sensible heat loss distribution in the sitting posture in various asymmetric radiant fields., Build. Environ., 42 (12), 3984-3999 (15 pages).

Spagnolo, J.; Dear, R., (2003). A field study of thermal comfort in outdoor and semi-outdoor environments in subtropical Sydney Australia. Build. Environ., 138 (5), 721-738 (18 pages).

Tian, Z.; Love, J., (2008). A field study of occupant thermal comfort and thermal environments with radiant slab cooling. Build. Environ., 43 (10), 1658-1670 (12 pages).

Willem, P. N.; Christopher, J., (2009). Implications of fossil fuel constraints on economic growth and global warming Energ. Policy, 37 (1), 166-180 (15 pages). 
Gh. R. Roshan et al.

Zaman, A. U., (2010). Comparative study of municipal solid waste treatment technologies using life cycle assessment method. Int. J. Environ. Sci. Tech., 7 (2), 225-234 (10 pages).
Zeiler, W.; Boxem, G., (2009). Effects on thermal activated building systems in schools on thermal comfort in winter. Build. Environ., 44 (11), 2308-2317 (10 pages).

\section{AUTHOR (S) BIOSKETCHES}

Roshan, Gh. R., Lecturer, Department of Geography, Golestan University; Ph.D. Candidate, Department of Physical Geography, University of Tehran, Tehran, Iran. Email: ghr.rowshan@gmail.com

Ranjbar, F., M.Sc. Student, Department of Physical Geography, University of Tehran, Tehran, Iran. Email: franjbar464@gmail.com

Orosa, J. A., Ph.D., Head of Department of Energy, University of A Coruña. A Coruña, Spain. Email: jaorosa@udc.es

How to cite this article: (Harvard style)

Roshan, Gh. R.; Ranjbar, F.; Orosa, J. A., (2010). Simulation of global warming effect on outdoor thermal comfort conditions. Int. J. Environ. Sci. Tech., 7 (3), 571-580. 